\title{
Crystal Structure and Cytotoxic Assay of a Novel Potential Anticancer Chalcone
}

\author{
Hamilton B. Napolitano ${ }^{1}$, Lidiane J. Michelini ${ }^{1,2}$, Jean M. F. Custodio ${ }^{1,2}$, Felipe T. Martins ${ }^{2}$ and Caridad N. \\ Perez $^{2}$ \\ ${ }^{1}$ Ciências Exatas e Tecnológicas, Universidade Estadual de Goiás, Anápolis, GO, Brazil \\ ${ }^{2}$ Instituto de Química, Universidade Federal de Goiás, Goiânia, GO, Brazil \\ *E-mail: hbnapolitano@gmail.com
}

Recently, a wide number of bioactivities has been discovered for chalcones. These applications depend on structural features such as planarity, electronic delocalization paths and substitution pattern on aromatic rings. This work aimed the structural analysis of a novel nitroaminochalcone $\left(\mathrm{C}_{17} \mathrm{H}_{12} \mathrm{O}_{3}\right.$, NAC) through single crystal X-ray diffraction technique and assessment of its cytotoxicity against tumor cells. NAC is almost completely planar, as evidenced by the low angle formed between its phenyl rings $\left[4.40(12)^{\circ}\right]$, which enables the $\pi$-electron delocalization through whole molecule. A resonance-assisted hydrogen bond (RAHB) is another interesting intramolecular feature of NAC, which is assembled between the amino and carbonyl groups into a cyclic $S(6)$ motif. The X-ray diffraction data were collected at room temperature using the Bruker APEX II CCD X-ray diffractometer $(\mathrm{MoK} \alpha$ radiation, $\lambda=0.71073 \AA$ ). From 11256 reflections collected [with 152 reflections rejected], the crystallographic structure was solved by direct methods and refined by least square on $F^{2}$ methods using SHELXS [1] software and refined by SHELXL [1] software $(R 1=0.0461$ and Goof $=1.054)$. The crystal packing is featured by the formation of dimers stabilized by a $R_{2}^{2}$ (16) motif engaging the carbonyl group and nitrobenzene. These dimers are organized in a $2 \mathrm{D}$ layer onto (010) through $\mathrm{C}-\mathrm{H} \cdots \mathrm{O}$ interactions involving the nitro e amine groups in a $C_{1}^{2}(13)\left[R_{1}^{2}(4)\right]$ motif. Furthermore, Hirshfeld surface analysis showed the crystal packing of NAC is also stabilized by both $\mathrm{C}-\mathrm{H} \cdots \pi$ and $\pi \cdots \pi$ interactions. The compound showed high cytotoxicity against human tumor cells.

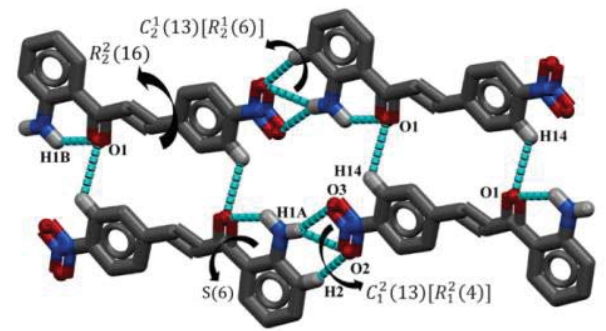

(a)

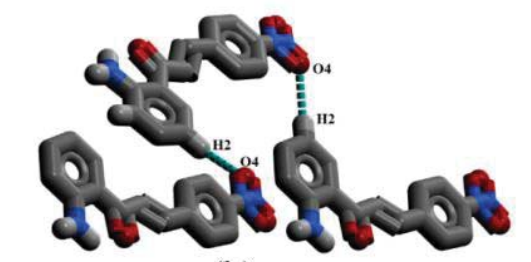

(b)

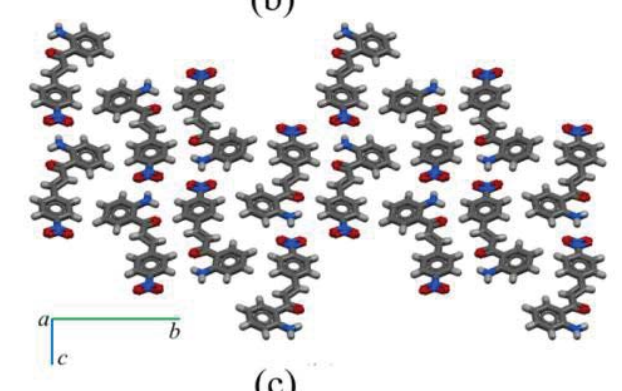

(c)

Figure 1: (a) The layer formed by $\mathrm{C} 14-\mathrm{H} 14 \cdot \bullet \mathrm{O} 1, \mathrm{C} 2-\mathrm{H} 2 \cdots \mathrm{O} 2, \mathrm{~N} 1-\mathrm{H} 1 \mathrm{~A} \cdots \mathrm{O} 3$ and $\mathrm{N} 1-\mathrm{H} 1 \mathrm{~A} \cdot \cdots \mathrm{O} 2$ interactions. (b) The nondimeric interaction $\mathrm{C} 2-\mathrm{H} 2 \cdots \mathrm{O} 4$. (c) A piece of the overall crystal packing of NAC.

The authors would like to thank Brazilian funding agencies CNPq, CAPES, and FAPEG for financial support and fellowships.

[1] G.M. Sheldrick, Crystal structure refinement with SHELXL, Acta Crystallogr. Sect. C Struct. Chem. 71 (2015) 3-8. doi:10.1107/S2053229614024218. 